\title{
Lauryl Phosphate Flotation Chemistry in Barite Flotation
}

\author{
Ying Lu ${ }^{1,2,+}$, Weiping Liu ${ }^{3, *}+{ }^{+}$, Xuming Wang ${ }^{1,3}{ }^{-}$, Huaigang Cheng ${ }^{1}$, Fangqin Cheng ${ }^{1, *}$ and \\ Jan D. Miller ${ }^{3}$ \\ 1 Institute of Resources and Environmental Engineering, State Environmental Protection Key Laboratory of \\ Efficient Utilization Technology of Coal Waste Resources, Shanxi Collaborative Innovation Center of High \\ Value-added Utilization of Coal-related Wastes, Shanxi University, No 92 Wucheng Road, Taiyuan 030006, \\ China; luying0813@163.com (Y.L.); x.wang@utah.edu (X.W.); chenghg@sxu.edu.cn (H.C.) \\ 2 Department of Environment and Safety Engineering, Taiyuan Institute of Technology, No 31 Xinlan Road, \\ Taiyuan 030008, China \\ 3 Department of Materials Science and Engineering, College of Mines and Earth Sciences, University of Utah, \\ 135 S 1460 E, Room 412, Salt Lake City, UT 84112-0114, USA; Jan.Miller@utah.edu \\ * Correspondence: wliu.met@gmail.com (W.L.); cfangqin@sxu.edu.cn (F.C.) \\ + These authors contributed equally to the work.
}

Received: 30 January 2020; Accepted: 9 March 2020; Published: 20 March 2020

check for updates

\begin{abstract}
Barite has numerous applications including barium mud for oil well drilling, manufacture of elemental barium, filler for paper and rubber industries, and contrast material for X-ray radiology for the digestive system. Currently, froth flotation is the main method for the beneficiation of barite using fatty acid as a typical collector. In this research, it was found that lauryl phosphate is also a promising collector for barite flotation. Results from microflotation, contact angle, and zeta potential indicate that lauryl phosphate is adsorbed on the barite surface and thus achieves superior flotation efficiency at a wide $\mathrm{pH}$ range. The interfacial water structure and wetting characteristics of barite surface with/without lauryl phosphate adsorption were also evaluated by molecular dynamics simulations (MDS). The results from molecular dynamics simulations and interaction energy calculations are in accord with the experimental results, which suggest that lauryl phosphate might be a potential collector for the flotation of barite.
\end{abstract}

Keywords: barite; lauryl phosphate; flotation

\section{Introduction}

Barite is a salt-type mineral with a chemical composition of $\mathrm{BaSO}_{4}$, which is crucial in many industries, such as petroleum, weighting material for drilling mud in natural gas operations, barium chemical productions [1], and functional barite materials [2,3]. Flotation is the main process for the recovery of barite from ores [4].

Sodium oleate and pine oil are typically used as collector and frother in barite flotation at $\mathrm{pH} 10[5,6]$. However, oleate is sensitive to slimes [7], low temperatures [8,9], and hard-water ions [10]. In this regard, many other collectors have been explored in barite flotation. Barite is either prefloated with cetyl stearyl sodium sulfate or depressed in apatite flotation using fatty acids at pH 12 [11]. Additionally, barite is selectively floated from fluorite using sodium petroleum sulfonate as a collector with sodium hexametaphosphate as a depressant at pH 11 [7]. Furthermore, barite is also a typical invaluable mineral from flotation of Mountain Pass bastnaesite [12]. Given the critical role of collector chemistry in barite flotation, more effective collectors are needed for high efficient separation. The phosphate collectors have been used in the flotation of calcite [13], perovskite, ilmenite and rutile, chromite [14], wolframite [15], magnesite [16], smithsonite [17], bastnaesite [18], and quartz [19]. The price of 
phosphate collectors is as low as the typical fatty acid collector [9]. For this reason, barite flotation using lauryl phosphate as collector was studied with respect to the effect of phosphate adsorption on contact angle and Zeta potential of barite surface. The results are important for understanding this phosphate chemistry in the flotation of barite from fluorite, apatite, and bastnaesite. Molecular dynamics simulations (MDS) examine the interfacial water structure at mineral surface [20], the water mobility [21], the hydrogen bond [22], and the adsorption sites of organic molecules at the mineral surface in solution $[18,23,24]$. In this regard, lauryl phosphate was evaluated as the collector in barite flotation for the first time by molecular dynamics simulations. The hydrophobicity, lauryl phosphate adsorption characteristics, flotation response, and reaction energy were examined and compared. It is expected that the present research will improve the fundamental understanding of lauryl phosphate adsorption at the barite surface, and its improved flotation efficiency for the separation of barite from fluorite, apatite, and bastnaesite.

\section{Materials and Methods}

\subsection{Materials}

Cola ${ }^{\circledR}$ Fax PME (potassium lauryl phosphate, $\mathrm{C}_{12} \mathrm{H}_{26} \mathrm{O}_{4} \mathrm{PK}$ ) was obtained from Colonial Chemical Incorporated Company, TN, USA). Barite from a mineral collection shop was used for the contact angle, zeta potential, and flotation experiments. Acetone, methanol, and deionized (DI) water were used to clean the glassware. DI water, with a resistivity larger than $18 \mathrm{~m} \Omega$, was used for all experiments. $\mathrm{pH}$ was adjusted by $\mathrm{HCl}$ and $\mathrm{NaOH}$ solutions. $\mathrm{KCl}$ was the background electrolyte in zeta potential measurements.

\subsection{Contact Angle Measurements}

The barite surface was polished and cleaned by the rinse with acetone, methanol, and DI water, followed by blow drying with high-purity nitrogen. The samples were then treated with argon gas plasma and again dried with high-purity nitrogen gas. Then, the captive bubble contact angle measurements were made by a Rame-Hart goniometer (Model 100-00-115, Reme-Hat, Inc. Mountain Lakes, NJ, USA). The measurement of an intermediate captive bubble contact angle was accomplished by the release of an air bubble from the needle tip after formation with a syringe; the bubble was then captured beneath the bastnaesite surface, followed by film rupture and bubble attachment [9]. The equilibrium contact angle was measured for all cases of attachment. The average value of five equilibrated captive bubble contact angles at different locations on the mineral surface was reported. The maximum contact angle variation was found to be $\pm 1^{\circ}[25,26]$. The equilibrium contact angle image was captured by a Kodak Ektapro high-speed video camera (Intensified Image, Eastman Kodak Company, Motion Analysis Division, San Diego, CA, USA) connected to the PC for data acquisition.

\subsection{Zeta Potential Measurements}

The lauryl phosphate solution, with a concentration of $5 \times 10^{-6} \mathrm{M}$, was prepared using $10 \mathrm{mM}$ $\mathrm{KCl}$ solution and Cola ${ }^{\circledR} \mathrm{Fax}$ PME reagent. The $\mathrm{pH}$ values were adjusted by $\mathrm{HCl}$ and $\mathrm{NaOH}$ solutions. The barite sample was dry ground to $-45 \mu \mathrm{m}$ and a $0.1 \mathrm{wt} \%$ suspension was prepared using $5 \times 10^{-6} \mathrm{M}$ lauryl phosphate with $10 \mathrm{mM} \mathrm{KCl}$. The suspension was treated with 10 min centrifugation and the supernatant was used in the determination of the electrophoretic mobilities by a Zeta potential analyzer (Zeta PALS, Brookhaven Instrument Corp, Holtsville, NY, USA). Based on the particle

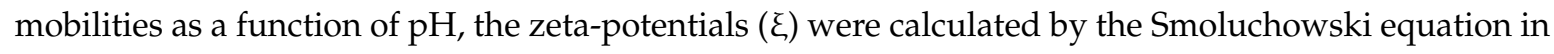
Equation (1) [27].

$$
U=\frac{\varepsilon \xi}{4 \pi \eta} E_{\infty}
$$

$U, \eta, \varepsilon$, and $E_{\infty}$ are the particle mobility $(\mathrm{m} / \mathrm{s})$, the viscosity of the solvent $(\mathrm{Pa} \cdot \mathrm{s})$, the dielectric constant $(F / m)$, and the applied electric field $(v / m)$, respectively. 


\subsection{Microflotation Tests}

A $-100+200$ mesh size fraction of barite was used for flotation. The flotation was conducted in a $112 \mathrm{~mL}$ column cell with a porous sintered glass bottom (pore size about $5 \mu \mathrm{m}$ ). A magnetic stirrer was used to maintain the particle suspending state for the microflotation experiment. One gram of barite with size fraction of $-100+200$ mesh was conditioned in the lauryl phosphate solution for 5 min and followed by $2 \mathrm{~min}$ flotation with $50 \mathrm{~mL} / \mathrm{min}$ nitrogen gas flow. The average recovery value from 3 microflotation tests was reported [28].

\subsection{Molecular Dynamics Simulations}

The lauryl phosphate structure was used from a previous paper using the Gaussian 09 program [29]. The crystal lattice parameters of barite were taken from the American Mineralogist Crystal Structure Database [30]. The barite (001) surface was used for the lauryl phosphate adsorption simulation [31]. The pKa of lauryl phosphate is 2.85 and 7.35, respectively [29]. The distribution of the lauryl phosphate species, such as $\mathrm{RH}_{2}, \mathrm{RH}^{-}$, and $\mathrm{R}^{2-}$ (R represents $\mathrm{C}_{12} \mathrm{H}_{25} \mathrm{PO}_{4}$ ), as a function of pH is summarized in Table 1. The interfacial adsorption state of the lauryl phosphate species at the barite surface was investigated by Amber [32]. Tables 1 and 2 list the number of atoms in molecular dynamics simulations and the intermolecular potential parameters. A periodic structure with a dimension of $27 \times 28 \times 126 \AA^{3}$ for the configuration of water, lauryl phosphate, and the barite surface was built by the visual molecular dynamics (VMD) graphics tool [33]. NVT [moles (N), volume (V), and temperature (T)] together with Hoover's thermostat were used. The integration of the particle motion was evaluated by the leap-frog method with a time step of $1 \mathrm{fs}$ (femtosecond). The electrostatic interactions were represented by the Ewald sum. A final 0.5 ns (nanosecond) simulation was analyzed after 1.5 ns equilibration period $[19,34]$.

Table 1. The composition and molecule number on the barite surface with lauryl phosphate species.

\begin{tabular}{cccccc}
\hline & \multicolumn{5}{c}{ Number of Molecules } \\
\cline { 2 - 5 } & $\mathbf{N a}^{+}$ & $\mathbf{R H}_{\mathbf{2}}$ & $\mathbf{R H}^{-}$ & $\mathbf{R}^{2-}$ & Water \\
\hline $\mathrm{pH}<2.85$ & & 6 & & & 2182 \\
$2.85<\mathrm{pH}<7.35$ & 6 & & 6 & & 2182 \\
$\mathrm{pH}>7.35$ & 12 & & & 6 & 2182 \\
\hline
\end{tabular}

Table 2. Parameters for barite with lauryl phosphate species.

\begin{tabular}{ccccc}
\hline Species & Charge [e] & $\mathcal{\varepsilon}[\mathbf{k c a l} / \mathbf{m o l}]$ & $\mathbf{r}[\AA ̊ \AA]$ & Reference \\
\hline Barium in barite & 2 & 0.364 & 3.703 & {$[35,36]$} \\
Sulfur in barite & 1.544 & 0.274 & 4.035 & {$[35,36]$} \\
Oxygen in barite & -0.886 & 0.1554 & 3.5536 & {$[35,37]$} \\
Water oxygen & -0.8476 & 0.1554 & 3.1659 & {$[37]$} \\
Water hydrogen & 0.4238 & 0 & 0 & {$[37]$} \\
\hline
\end{tabular}

The distribution of the molecules at the mineral surface is described by the relative concentration profiles in Equation (2) [22]. $N(Z-0.5 \Delta Z, Z+0.5 \Delta Z)$ is the average atom number appearing in the duration of $(Z-0.5 \Delta Z, Z+0.5 \Delta Z)(\Delta z=0.01)$. M and $S$ are atom mass and the basal surface area, respectively.

$$
\rho_{z}=\frac{N(Z-0.5 \Delta Z, Z+0.5 \Delta Z) \times M}{\Delta Z \times S}
$$


The diffusion coefficient $(D)$ was calculated by Equation (3) [34], where $N_{a}$ is the diffusive atom number; $r_{i}(0)$ and $r_{i}(t)$ are the mass center positions of the solutes at the time of origin and $t$, respectively.

$$
D=\frac{1}{6 N_{a}} \lim _{t \rightarrow \infty} \sum_{i=1}^{N_{a}}\left\langle\left[r_{i}(t)-r_{i}(0)\right]^{2}\right\rangle
$$

The mineral surface-lauryl phosphate/water interaction energy, $\Delta \mathrm{E}$, was computed by Equation (4):

$$
\Delta E=E_{\text {complex }}-\left(E_{\text {mineral surface }}+E_{\text {reagent }}\right)
$$

where $E_{\text {complex }}, E_{\text {mineral surface, }}$ and $E_{\text {reagent }}$ are the interaction energies of the optimized mineral surface-reagent complex, mineral surface, and reagent such as water and lauryl phosphate. The more negative values of the interaction energy of $\Delta E$ represent the greater interactions between the mineral surface and the reagent [19].

\section{Result and Discussion}

The flotation chemistry of barite is critical in the separation of barite from apatite, fluorite, and bastnaesite. For this reason, the wetting characteristics, lauryl phosphate adsorption phenomena, and flotation response in barite flotation with lauryl phosphate were examined by contact angle and zeta potential measurements, microflotation, and molecular dynamics simulations.

\subsection{Contact Angle of Barite with Lauryl Phosphate}

Contact angle measurements evaluate the hydrophobicity of the mineral, which describes the repulsion or rejection of water at the mineral surface [38]. In this regard, the contact angles at the barite surface with lauryl phosphate, as a function of $\mathrm{pH}$ and concentration, are presented in Figures 1 and 2. As shown in Figures $1 \mathrm{a}$ and $2 \mathrm{a}$, the contact angle of barite is around $40^{\circ}$ at $\mathrm{pH} 6.6$ and $\mathrm{pH} 9.3$, which is higher than the value of $35^{\circ}$ at $\mathrm{pH} 3.0$. As for the contact angle of barite as a function of lauryl phosphate concentration in Figures $1 \mathrm{~b}$ and $2 \mathrm{~b}$, the contact angle increased from $20^{\circ}$ at the fresh barite surface to $60^{\circ}$ in the presence of $1 \times 10^{-4} \mathrm{M}$ lauryl phosphate. It is evident that bubble rupture occurs at the barite surface and replaces the surface water reaching equilibrium state from $1 \times 10^{-5} \mathrm{M}$ to $1 \times 10^{-4} \mathrm{M}$ lauryl phosphate concentration in Figure $2 \mathrm{~b}$. The bubble captive contact angle of $20^{\circ}$ at a fresh barite surface is smaller than the reported sessile drop value of $38^{\circ}$ [39]. The contact angle deviations may be due to the differences in experimental methods and conditions [40].
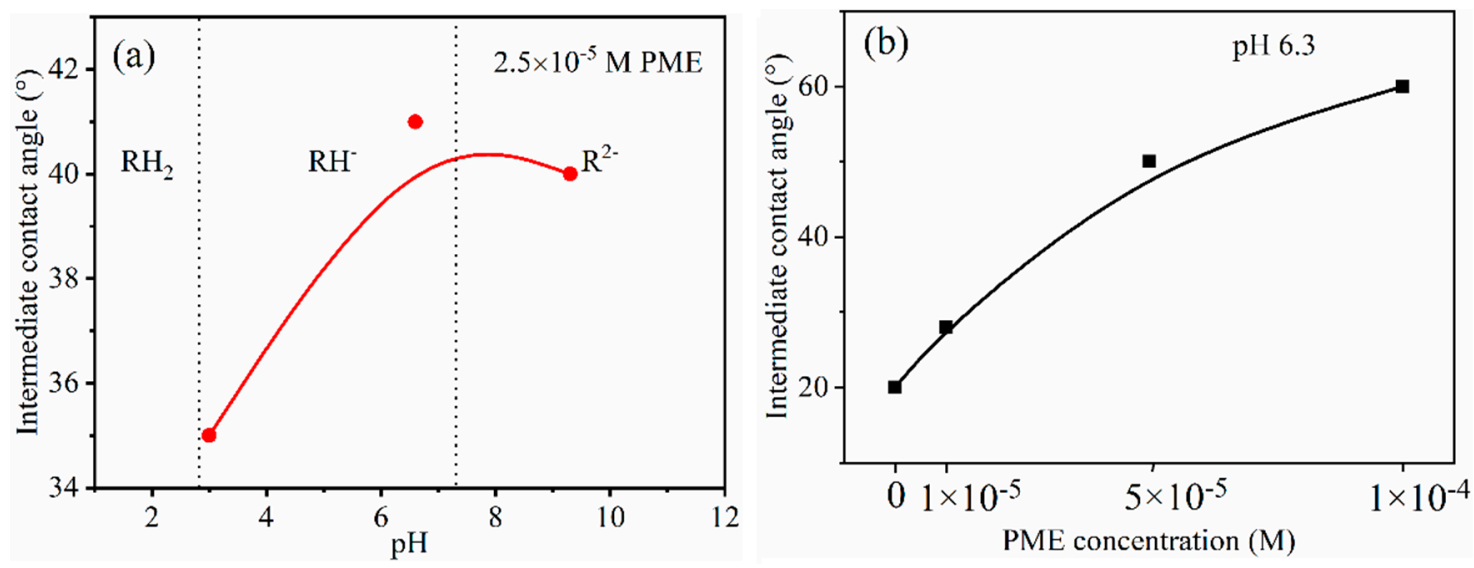

Figure 1. Intermediate contact angle of barite with lauryl phosphate (PME) as a function of $\mathrm{pH}(\mathbf{a})$ and concentration $(\mathbf{b})$. 
(a)

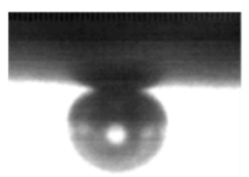

pH 3.0

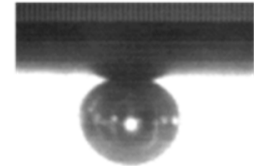

pH 6.6

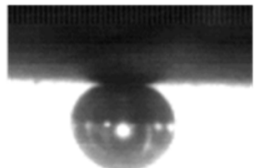

pH 9.3 (b)

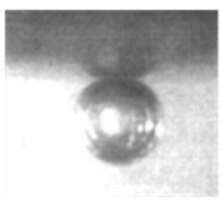

0 M PME

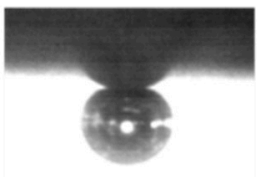

$1 \times 10^{-5} \mathrm{M}$ PME

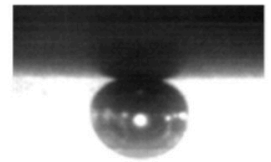

$5 \times 10^{-5} \mathrm{M}$ PME

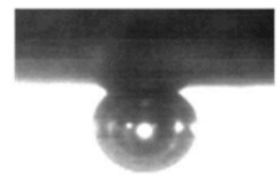

$1 \times 10^{-4} \mathrm{M}$ PME

Figure 2. Captive bubble contact angle at a barite surface with $2.5 \times 10^{-5} \mathrm{M} \mathrm{PME}$ as a function of $\mathrm{pH}$ (a); and captive bubble contact angle at a barite surface with pH 6.3 as a function of PME concentration (b).

\subsection{Zeta Potential of Barite with Lauryl Phosphate}

Zeta potentials examine the potential difference between the dispersing mineral particles and the attached stationary water layer. For this reason, the change of zeta potential due to the adsorption of the collector/depressant may be indicative of the hydrophobicity/flotation response [34]. As shown in Figure 3, the IEP (isoelectric point) of barite is about $\mathrm{pH}$ 5.5, which is close to the reported value of 4.7 [7]. The zeta potential of barite decreased around $4-8 \mathrm{mV}$ in the presence of lauryl phosphate when compared to the barite without lauryl phosphate adsorption, which indicates significant adsorption of anionic lauryl phosphate at the barite surface as a function of $\mathrm{pH}$. As lauryl phosphate is an anionic collector at $\mathrm{pH}>5.5$ (the IEP of barite), the mechanism of adsorption onto the barite surface must be chemisorption due to the electrostatic repulsion caused by the negative charge barite surface at alkaline $\mathrm{pH}$. For the $\mathrm{pH}$ range less than 5.5, it is not possible from zeta potential data alone to predict the collector adsorption mechanism, as in acidic conditions, the positive barite surface charge will attract the lauryl phosphate anion. In this regard, the physisorption and a possible chemisorption were expected at $\mathrm{pH}$ less than 5.5. Further research is needed regarding the adsorption feature at lower concentration, such as the adsorption coverage and/or density effect on barite surface hydrophobicity, and comparison of a traditional collector with lauryl phosphate.

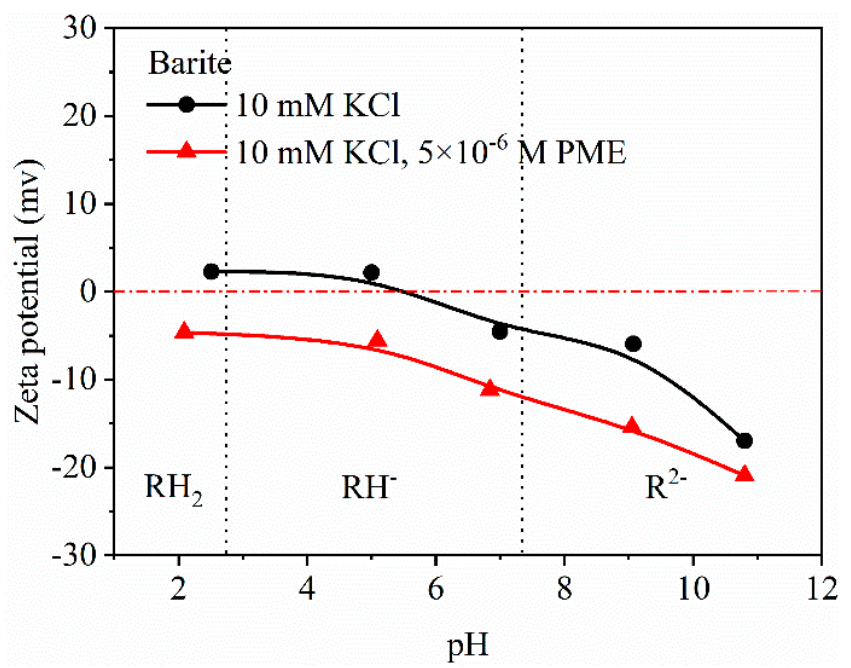

Figure 3. Barite zeta potential with and without the adsorption of lauryl phosphate (PME). 


\subsection{Barite Flotation with Lauryl Phosphate}

The results from barite flotation using lauryl phosphate as a collector is shown in Figure 4 . It is obvious that the barite flotation recovery increases as a function of lauryl phosphate concentration at different $\mathrm{pH}$. Furthermore, all the barite recovery reaches $95 \%$ at $1 \times 10^{-5} \mathrm{M}$ lauryl phosphate concentration for $\mathrm{pH} 3.0, \mathrm{pH} 6.3$, and $\mathrm{pH}$ 9.5. However, the barite recovery for $\mathrm{pH} 3$ is lower than the barite recovery at $\mathrm{pH} 6.3$ and $\mathrm{pH} 9.5$ when lauryl phosphate concentration is less than $1 \times 10^{-5} \mathrm{M}$. The main lauryl phosphate species is $\mathrm{RH}_{2}$, when $\mathrm{pH}$ less than $\mathrm{pH} 3$, which is more hydrophobic and lower in solubility when compared to the $\mathrm{RH}^{-}$and $\mathrm{R}^{2-}$ species [9]. In this regard, $\mathrm{RH}_{2}$ tends to be adsorbed at the air/water interface instead of air/mineral interface [41]. For this reason, the barite recovery at $\mathrm{pH} 3.0$ is less than $\mathrm{pH} 6.3$ and $\mathrm{pH} 9.5$ at low lauryl phosphate concentration of $1 \times 10^{-5} \mathrm{M}$. When lauryl phosphate concentration increased above $1 \times 10^{-5} \mathrm{M}$, the lauryl phosphate species $\mathrm{RH}_{2}$ accumulated at the barite surface as an aggregate [41], and thus resulted in the high barite recovery of $95 \%$.

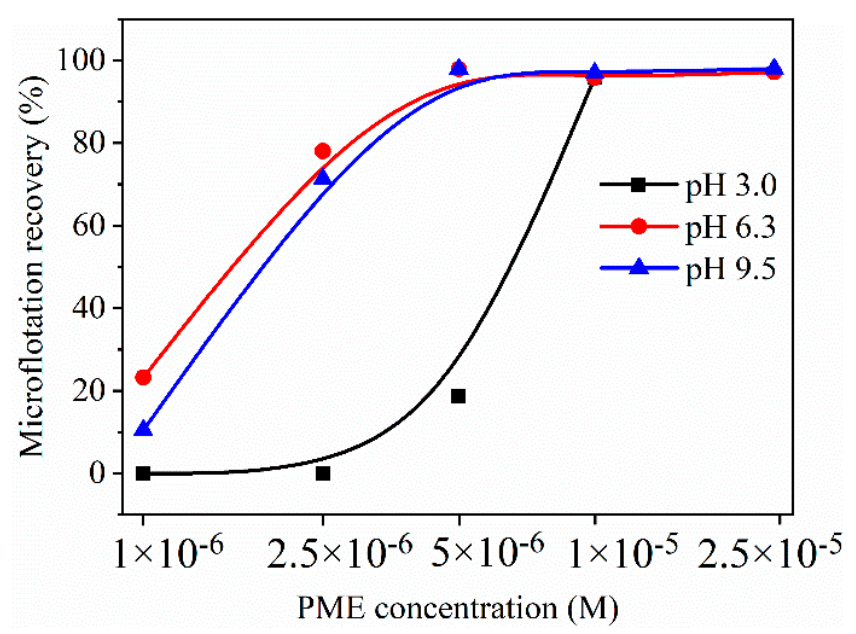

Figure 4. Barite flotation response as a function of lauryl phosphate concentration at $\mathrm{pH} 3.0, \mathrm{pH} 6.3$, and $\mathrm{pH} 9.5$.

\subsection{MDS of Lauryl Phosphate Adsorption at the Barite Surface}

The equilibrated lauryl phosphate species such as $\mathrm{RH}_{2}, \mathrm{RH}^{-}$, and $\mathrm{R}^{2-}$ on the barite (001) surface are shown in Figure 5. It is obvious that the adsorption states of lauryl phosphate species are not the same due to its different charge/composition in nature. However, all the lauryl phosphate species are adsorbed mainly by the adsorption of phosphate head group toward the barite (001) surface and also the hydrophobic attraction between the hydrocarbon chains of lauryl phosphate. The interaction of the phosphate head group with barite surface seems to be chemisorption, which agrees with the zeta potential measurement result and the low solubility product of $6 \times 10^{-39}$ for $(\mathrm{Ba})_{3}\left(\mathrm{PO}_{4}\right)_{2}[42]$.

The relative concentration of lauryl phosphate and water molecules at the barite (001) surface was analyzed in Figure 6. It is obvious that the water density decreased in the presence of lauryl phosphate species as a function of distance from the barite surface. There is limited water density decreasing at the first peak in the presence of lauryl phosphate species, which indicates that the barite surface is mainly occupied by water molecules, and thus the water coexisted with the lauryl phosphate species at the barite surface. The above observation agrees with the lauryl phosphate adsorption phenomena as shown in Figure 5 and further confirmed that the barite surface is hydrophilic [43]. As for the second water peak to the fifth water peak in Figure 6a, it is evident that the water density decreased a lot when compared to the first water peak, which confirmed that lauryl phosphate species replaced the water molecules, and thus created a hydrophobic surface. The relative density of lauryl phosphate species from the barite (001) surface is almost the same in Figure 6b, which agrees with the flotation result in Figure 4 at lauryl phosphate concentration larger than $1 \times 10^{-5} \mathrm{M}$. 
(a)

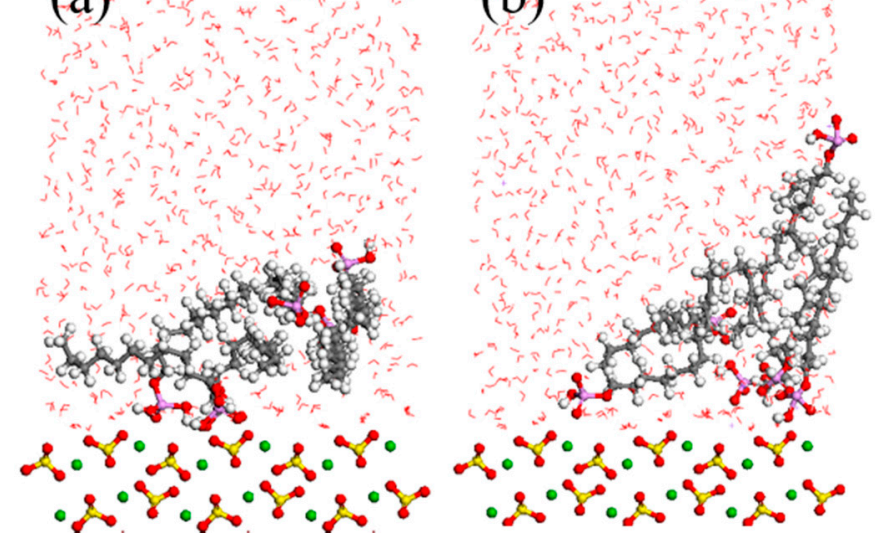

(c)

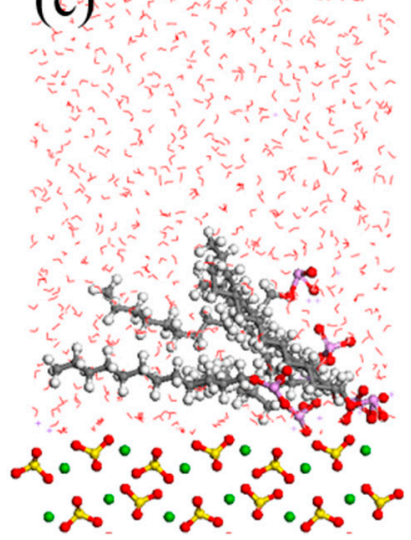

Figure 5. Interfacial behavior of lauryl phosphate species (a) $\mathrm{RH}_{2}$, (b) $\mathrm{RH}^{-}$, and (c) $\mathrm{R}^{2-}$ at barite (001) surface.
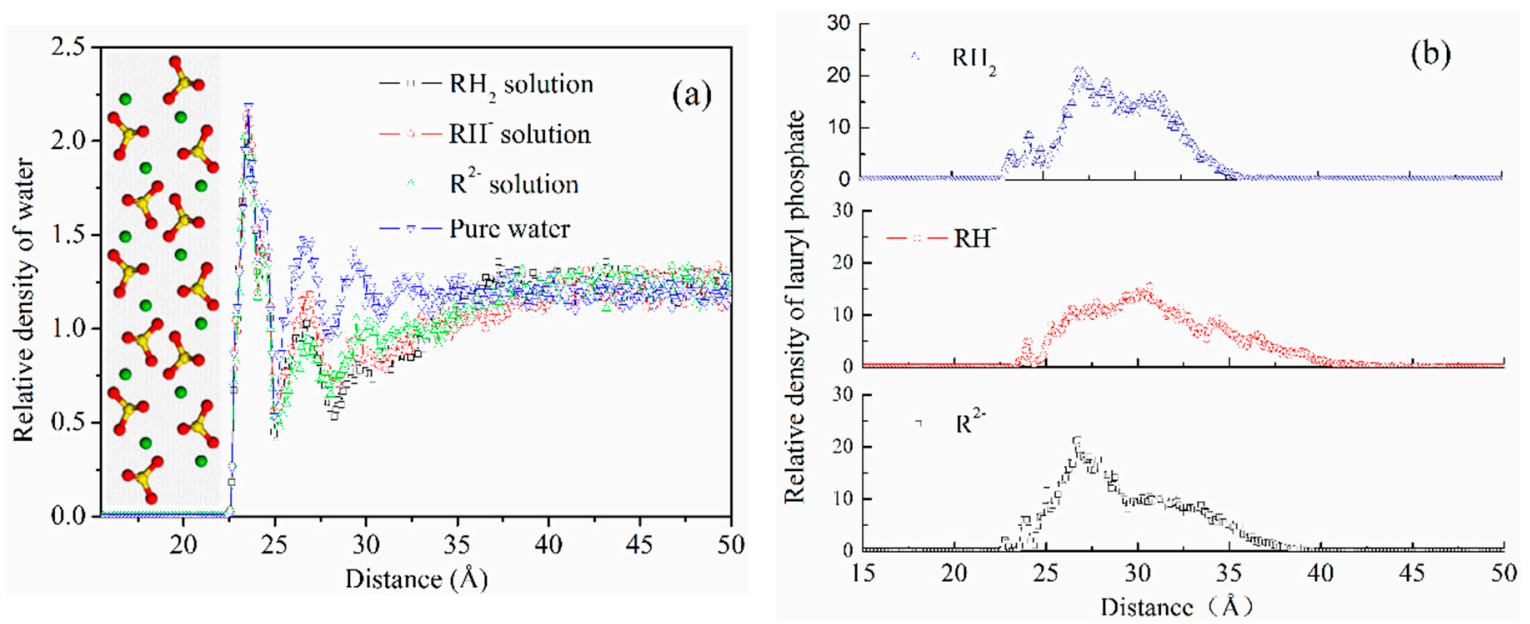

Figure 6. Relative density distribution of molecules/atoms along the normal to barite (001) basal plane surfaces. Water (a) and lauryl phosphate species (b).

The diffusion coefficient (D) and mean square displacement examine the molecules' displacement as a function of time [34]. The high diffusion coefficient of water at mineral surface represents a disordered and less structured interfacial water state at the mineral surface. On the contrary, the low diffusion coefficient of water molecules at the mineral surface indicates the ordered and structured interfacial water state at the mineral surface [34,44]. As shown in Table 3 and Figure 7 , the diffusion coefficient of water in the presence of lauryl phosphate species changed in the range of $4.71-5.77 \times 10^{-5} \mathrm{~cm}^{2} / \mathrm{s}$, which is expected as the water contacts with lauryl phosphate species with different charges. However, the above diffusion coefficient of water in the presence of lauryl phosphate is higher than the value of $3.84 \times 10^{-5} \mathrm{~cm}^{2} / \mathrm{s}$ for the pure water. In this regard, the lauryl phosphate species replaced the water molecules at the barite surface and thus created a disordered and less structured interfacial water state with a higher diffusion coefficient. The same phenomenon has been found in the oleate chemisorption at the calcite and fluorite surfaces [45], alkyl phosphate chemisorption at the bastnaesite surface [34], and fatty acids chemisorption at brucite surface [20]. 
Table 3. Diffusion coefficient $(D)$ for interfacial water molecules in the system of pure water, $\mathrm{RH}_{2}, \mathrm{RH}^{-}$, and $\mathrm{R}^{2-}$ solutions on barite (001) surface as obtained from their mean square displacements.

\begin{tabular}{|c|c|}
\hline System & $D\left(10^{-5} \mathrm{~cm}^{2} / \mathrm{s}\right)$ \\
\hline Pure water & 3.84 \\
\hline $\mathrm{RH}_{2}$ solution & 4.71 \\
\hline $\mathrm{RH}^{-}$solution & 5.69 \\
\hline $\mathrm{R}^{2-}$ solution & 5.77 \\
\hline
\end{tabular}

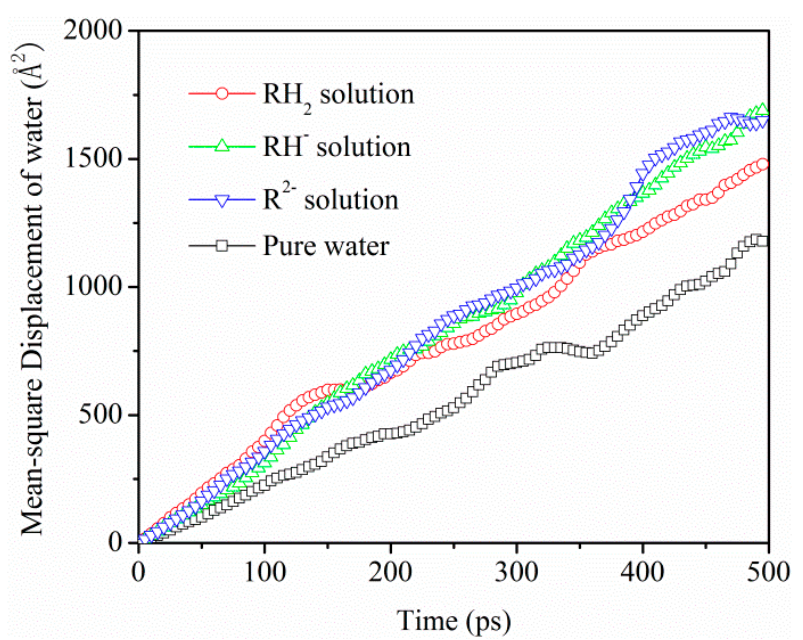

Figure 7. Mean square displacement of water in the system of pure water, $\mathrm{RH}_{2}, \mathrm{RH}^{-}$, and $\mathrm{R}^{2-}$ solutions on barite (001) surface.

\subsection{Interaction Energy of Lauryl Phosphate Species at the Barite Surface}

The interaction energies of water and lauryl phosphate species at the barite (001) surface are presented in Figure 8. A negative interaction energy value represents stronger adsorption of water/lauryl phosphate species at the barite surface. The interaction energy for lauryl phosphate species at the barite surface is smaller than the case for water, which indicate that all lauryl phosphate species are able to replace water and adsorb at the barite surface. However, the interaction energy of $\mathrm{RH}_{2}$ at the barite surface is larger than the case of $\mathrm{RH}^{-}$and $\mathrm{R}^{2-}$ at the barite (001) surface, which is in accord with the flotation result that $\mathrm{RH}_{2}$ has lower barite flotation recovery than $\mathrm{RH}^{-}$and $\mathrm{R}^{2-}$ at low lauryl phosphate concentration of less than $1 \times 10^{-5} \mathrm{M}$. The interaction energy difference for $\mathrm{RH}^{-}$and $\mathrm{R}^{2-}$ at the barite surface is only $5 \mathrm{~kJ} / \mathrm{mol}$, which also agrees with findings that the contact angle measurement results, and the flotation recoveries are similar at mild and alkaline $\mathrm{pH}$ range.

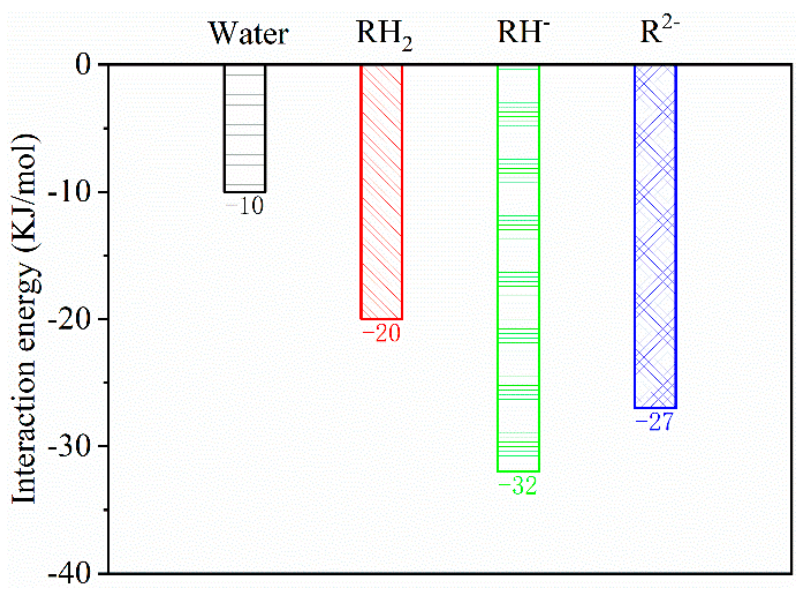

Figure 8. Interaction energy of water, $\mathrm{RH}_{2}, \mathrm{RH}^{-}$, and $\mathrm{R}^{2-}$ on the barite (001) surface. 


\section{Conclusions}

The wetting characteristics, lauryl phosphate adsorption phenomena, and flotation response in barite flotation with lauryl phosphate were studied by contact angle, zeta potential, and microflotation experiments, and molecular dynamics simulations. It seems that lauryl phosphate can be adsorbed on barite surface at all $\mathrm{pH}$ ranges at a low dosage of $1 \times 10^{-5} \mathrm{M}$ and achieved $95 \%$ barite flotation recovery. Lauryl phosphate is a potential collector in the flotation of barite from fluorite or apatite. Further research efforts are needed to further evaluate the selectivity of lauryl phosphate in the direct/reverse flotation of barite from fluorite, apatite, and bastnaesite, and the specific depressant is also needed. Conclusions at this time are as follows:

(1) Lauryl phosphate results in higher hydrophobicity of barite in mild and alkaline $\mathrm{pH}$ range when compared to acid $\mathrm{pH}$ range at low concentration.

(2) A $95 \%$ barite flotation recovery can be achieved at a wide $\mathrm{pH}$ range using lauryl phosphate as collector with a low usage of $1 \times 10^{-5} \mathrm{M}$.

(3) The adsorption of anionic lauryl phosphate at the barite surface seems to be chemisorption at $\mathrm{pH}$ higher than $\mathrm{pH} 5.5$ and a mixture of physisorption and/or chemisorption at $\mathrm{pH}$ less than 5.5.

(4) Lauryl phosphate species replaced water and adsorbed at the barite surface at all $\mathrm{pH}$ ranges from interaction energy calculation and molecular dynamics simulations examinations.

Author Contributions: Conceptualization, Y.L. and W.L.; methodology, Y.L. and W.L.; software, W.L.; validation, Y.L., W.L. and X.W.; formal analysis, Y.L., W.L. and X.W.; investigation, Y.L. and W.L.; resources, X.W., F.C. and J.D.M.; data curation, Y.L., W.L. and X.W.; writing-original draft preparation, Y.L. and W.L.; writing一review and editing, W.L. and X.W.; visualization, W.L. and X.W.; supervision, X.W., H.C., F.C. and J.D.M.; project administration, X.W. and F.C.; funding acquisition, F.C. All authors have read and agreed to the published version of the manuscript.

Funding: This research was funded by National Natural Science Foundation of China (Grant No. U1810205) and the National Key Research and Development Plan of China (Grant No. 2017YFB0603100).

Acknowledgments: The Gaussian calculation and Amber were enabled by the Center for High-Performance Computing at the University of Utah.

Conflicts of Interest: The authors declare no conflict of interest.

\section{Notation:}

$\begin{array}{ll}\rho_{z} & \text { density profiles } \\ N & \text { Moles } \\ V & \text { Volume } \\ T & \text { Temperature } \\ M & \text { atomic mass } \\ S & \text { basal surface area } \\ D & \text { diffusion coefficients } \\ N_{a} & \text { number of diffusive atoms in the simulation cell } \\ r_{i}(0) & \text { mass center positions of the solutes at the time of origin } \\ r_{i}(t) & \text { mass center positions of the solutes at the time of t } \\ \Delta E & \text { interaction energy } \\ E_{\text {complex }} & \text { interaction energies of the optimized mineral surface-reagent complex } \\ E_{\text {mineral surface }} & \text { interaction energy of mineral surface } \\ E_{\text {reagent }} & \text { interaction energy of reagent such as water and lauryl phosphate }\end{array}$

\section{References}

1. Akkurt, I.; Basyigit, C.; Kilincarslan, S.; Mavi, B. The shielding of $\gamma$-rays by concretes produced with barite. Prog. Nucl. Energy 2005, 46, 1-11. [CrossRef]

2. Sun, S.; Ding, H.; Zhou, H. Preparation of TiO2-coated barite composite pigments by the hydrophobic aggregation method and their structure and properties. Sci. Rep. 2017, 7, 10083. [CrossRef] 
3. Bahl, S.; Lochab, S.P.; Pandey, A.; Kumar, V.; Aleynikov, V.E.; Molokanov, A.G.; Kumar, P. Characterization and luminescence studies of Eu doped Barite nanophosphor. J. Lumin. 2014, 149, 176-184. [CrossRef]

4. Yekeler, M.; Ulusoy, U. Characterisation of surface roughness and wettability of salt-type minerals: Calcite and barite. Miner. Process. Extr. Metall. 2004, 113, 145-152. [CrossRef]

5. Gurpinar, G.; Sonmez, E.; Bozkurt, V. Effect of ultrasonic treatment on flotation of calcite, barite and quartz. Miner. Process. Extr. Metall. 2004, 113, 91-95. [CrossRef]

6. Marinakis, K.I.; Shergold, H.L. Influence of sodium silicate addition on the adsorption of oleic acid by fluorite, calcite and barite. Int. J. Miner. Process. 1985, 14, 177-193. [CrossRef]

7. Chen, Z.; Ren, Z.; Gao, H.; Zheng, R.; Jin, Y.; Niu, C. Flotation studies of fluorite and barite with sodium petroleum sulfonate and sodium hexametaphosphate. J. Mater. Res. Technol. 2019, 8, 1267-1273. [CrossRef]

8. Chen, C.; Zhu, H.; Sun, W.; Hu, Y.; Qin, W.; Liu, R. Synergetic effect of the mixed anionic/non-ionic collectors in low temperature flotation of scheelite. Minerals 2017, 7, 87. [CrossRef]

9. Liu, W.; Wang, X.; Wang, Z.; Miller, J.D. Flotation chemistry features in bastnaesite flotation with potassium lauryl phosphate. Miner. Eng. 2016, 85, 17-22. [CrossRef]

10. Cao, Q.; Cheng, J.; Wen, S.; Li, C.; Liu, J. Synergistic effect of dodecyl sulfonate on apatite flotation with fatty acid collector. Sep. Sci. Technol. 2016, 51, 1389-1396. [CrossRef]

11. Guimarães, R.C.; Araujo, A.C.; Peres, A.E.C. Reagents in igneous phosphate ores flotation. Miner. Eng. 2005, 18, 199-204. [CrossRef]

12. Fuerstenau, D.W. A century of research leading to understanding the scientific basis of selective mineral flotation and design of flotation collectors. Miner. Metall. Explor. 2019, 36, 3-20. [CrossRef]

13. Seth, V.; Kumar, R.; Arora, S.C.D.; Biswas, A.K. Disodium dodecyl phosphate as a collector in the calcite-apatite mineral system. Trans. Inst. Miner. Metall. 1975, 84, 56-58.

14. Bulatovic, S.; Wyslouzil, D.M. Process development for treatment of complex perovskite, ilmenite and rutile ores. Miner. Eng. 1999, 12, 1407-1417. [CrossRef]

15. Srinivas, K.; Sreenivas, T.; Padmanabhan, N.P.H.; Venugopal, R. Studies on the application of alkyl phosphoric acid ester in the flotation of wolframite. Miner. Process. Extr. Metall. Rev. 2004, 25, 253-267. [CrossRef]

16. Chen, G.L.; Tao, D. Reverse flotation of magnesite by dodecyl phosphate from dolomite in the presence of sodium silicate. Sep. Sci. Technol. 2005, 39, 377-390. [CrossRef]

17. Liu, W.; Wang, Z.; Wang, X.; Miller, J.D. Smithsonite flotation with lauryl phosphate. Miner. Eng. 2020, 147, 106-155. [CrossRef]

18. Liu, W.; Wang, X.; Miller, J.D. Collector chemistry for bastnaesite flotation-Recent developments. Miner. Process. Extr. Metall. Rev. 2019, 40,370-379. [CrossRef]

19. Liu, W.; Wang, X.; Xu, H.; Miller, J.D. Physical chemistry considerations in the selective flotation of bastnaesite with lauryl phosphate. Miner. Metall. Explor. 2017, 34, 116-124. [CrossRef]

20. Liu, W.; Xu, H.; Wang, Z.; Wang, X. Adsorption features of water molecules and fatty acids at magnesium hydroxide surface from an MDS perspective. Surf. Innov. 2019, 7, 304-316. [CrossRef]

21. Liu, W.; Xu, H.; Wang, Z.; Wang, X. Simulation of fatty acid adsorption at the magnesia surface. Surf. Innov. 2020, 8, 1-10. [CrossRef]

22. Lu, Y.; Wang, X.; Liu, W.; Li, E.; Cheng, F.; Miller, J.D. Dispersion behavior and attachment of high internal phase water-in-oil emulsion droplets during fine coal flotation. Fuel 2019, 253, 273-282. [CrossRef]

23. Liu, W.; Miller, J.D. Higher selectivity of diisobutyl monothiophosphate in the flotation of elemental gold from pyrite. In Proceedings of the 42nd International Precious Metals Institute Annual Conference, San Antonio, TX, USA, 9-12 June 2018.

24. Gao, Z.; Sun, W.; Hu, Y. New insights into the dodecylamine adsorption on scheelite and calcite: An adsorption model. Miner. Eng. 2015, 79, 54-61. [CrossRef]

25. Drelich, J.; Wilbur, J.L.; Miller, J.D.; Whitesides, G.M. Contact angles for liquid drops at a model heterogeneous surface consisting of alternating and parallel hydrophobic/hydrophilic strips. Langmuir 1996, 12, 1913-1922. [CrossRef]

26. Lam, C.N.C.; Wu, R.; Li, D.; Hair, M.L.; Neumann, A.W. Study of the advancing and receding contact angles: Liquid sorption as a cause of contact angle hysteresis. Adv. Colloid Interface 2002, 96, 169-191. [CrossRef]

27. Delgado, A.V.; González-Caballero, F.; Hunter, R.J.; Koopal, L.K.; Lyklema, J. Measurement and interpretation of electrokinetic phenomena (IUPAC Technical Report). Pure Appl. Chem. 2005, 77, 1753-1805. [CrossRef] 
28. Ergen, G.; Özün, S.; Liu, W. Investigation of the effect of straight-chain xanthates on galena flotation depending on collector concentration and air flow rate (AFR). In Proceedings of the 26th International Mining Congress and Exhibition of Turkey, Belek, Turkey, 16-19 April 2019; Volume 1, pp. 787-794.

29. Liu, W.; Wang, X.; Xu, H.; Miller, J.D. Lauryl phosphate adsorption in the flotation of bastnaesite, $(\mathrm{Ce}, \mathrm{La}) \mathrm{FCO}_{3}$. J. Colloid Interface Sci. 2017, 490, 825-833. [CrossRef]

30. Colville, A.A.; Staudhammer, K. A refinement of the structure of barite. Am. Miner. J. Earth Planet. Mater. 1967, 52, 1877-1880.

31. Bracco, J.N.; Lee, S.S.; Stubbs, J.E.; Eng, P.J.; Heberling, F.; Fenter, P.; Stack, A.G. Hydration structure of the barite (001)-water interface: Comparison of x-ray reflectivity with molecular dynamics simulations. J. Phys. Chem. C 2017, 121, 12236-12248. [CrossRef]

32. Case, D.A.; Babin, V.; Berryman, J.T.; Betz, R.M.; Cai, Q.; Cerutti, D.S.; Darden, T.A.; Duke, R.E.; Gohlke, H.; Götz, A.W.; et al. AMBER 14; University of California: San Francisco, CA, USA, 2014.

33. Humphrey, W.; Dalke, A.; Schulten, K. VMD: Visual molecular dynamics. J. Mol. Graph. Model. 1996, 14, 33-38. [CrossRef]

34. Liu, W.; McDonald, I.; Luther, W.; Wang, X.; Miller, J.D. Bastnaesite flotation chemistry issues associated with alkyl phosphate collectors. Miner. Eng. 2018, 127, 286-295. [CrossRef]

35. Stack, A.G. Molecular dynamics simulations of solvation and Kink Site formation at the (001) Barite-Water interface. J. Phys. Chem. C 2008, 113, 2104-2110. [CrossRef]

36. Rappé, A.K.; Casewit, C.J.; Colwell, K.S.; Goddard, W.A., III; Skiff, W.M. UFF, a full periodic table force field for molecular mechanics and molecular dynamics simulations. J. Am. Chem. Soc. 1992, 114, 10024-10035. [CrossRef]

37. Berendsen, H.J.C.; Grigera, J.R.; Straatsma, T.P. The missing term in effective pair potentials. J. Phys. Chem. 1987, 91, 6269-6271. [CrossRef]

38. Veeramasuneni, S.; Drelich, J.; Miller, J.D.; Yamauchi, G. Hydrophobicity of ion-plated PTFE coatings. Prog. Organ. Coat. 1997, 31, 265-270. [CrossRef]

39. Chen, Z.; Ren, Z.; Gao, H.; Qian, Y.; Zheng, R. Effect of modified starch on separation of fluorite from barite using sodium oleate. Physicochem. Probl. Miner. Process. 2018, 54, 228-237.

40. Drelich, J.W.; Boinovich, L.; Chibowski, E.; Della Volpe, C.; Hołysz, L.; Marmur, A.; Siboni, S. Contact angles: History of over 200 years of open questions. Surf. Innov. 2019, 8, 3-27. [CrossRef]

41. Nakayama, K.; Tari, I.; Sakai, M.; Murata, Y.; Sugihara, G. Aggregation behavior of sodium mono-n-dodecyl phosphate surfactant in aqueous media, and function in catalytic activity. I. Multi-step aggregates formation and catalytic activity for hydrolysis of p-nitrophenyl acetate in aqueous solution. J. Oleo Sci. 2004, 53, 247-265.

42. Lichstein, B.; Woolf, C. Process for removal of phosphates from solutions containing fluoride ions. US Patent 3,755,546, 1973.

43. Sadowski, Z. The spherical oil agglomeration of barite suspensions in the presence of surfactant and cosurfactant. Colloid Surf. A 1993, 80,147-152. [CrossRef]

44. Burkin, A.R. The Chemistry of Hydrometallurgical Processes; D. Van Nostrand Co.: Princeton, NJ, USA, 1972.

45. Young, C.; Miller, J.D. Thermodynamic evaluation of oleate chemisorption at calcium semi-soluble salt surfaces. In Proceedings of the International Conference on Advances in Materials and Materials Processing, ICAMMP-2002, Kharagpur, India, 1-3 February 2002; Tata McGraw-Hill: New Delhi, India; pp. 793-805.

(C) 2020 by the authors. Licensee MDPI, Basel, Switzerland. This article is an open access article distributed under the terms and conditions of the Creative Commons Attribution (CC BY) license (http://creativecommons.org/licenses/by/4.0/). 